CASG STUDIES IN INSOMNIA. P.J. HAURI, editor. Um volume $(15,5 \times 23,5 \mathrm{~cm})$ encadernado, com 254 páginas. New York: Plenum Publishing Co, 1991. Preço US\$ 47.20. Endereço: Plenum Publ Co, 233 Spring Street, New York, NY 10013, USA.

Unindo um grupo de 26 clínicos e pesquisadores dos EUA, Peter J. Hauri edita uma monografia de peso, com dados recentes desta queixa tão comum, a insônia e, principalmente, do seu tratamento. Do conjunto de colaboradores participam vários expoentes no campo da insônia, como R.R. Bootzin, A.J. Spielman, P.B. Glovinsky e T. Roth. O prefácio é assinado por um dos patriarcas de toda a pesquisa de sono, W.C. Dement.

E interessante ver como la insônia ao invés de se mostrar mais simples e de terapêtica melhor esquematizada e eficaz, após décadas de pesquisa e submetida aos novos métodos diagnósticos, mostra-se cada vez mais complexa. O diagnóstico diferencial do paciente insone inclui, hoje, diversas afecçōes praticamente desconhecidas há poucos anos, indo desde a sindrome de avanço da fase de sono, às mioclonias noturnas e ao acometimento sazonal do humor. No tratamento, além das psicoterapias, é dada ênfase às medidas de higiene do sono, às terapias comportamentais, incluindo relaxamento e intervenção cognitiva, e ao tratamento medicamentoso. Do último grupo, são focalizados o emprego de benzodiazepinas e de antidepressivos. Menciona em detalhes as dificuldades na orientaçăo do idoso e dos pacientes com insônia associada a patologias de longa evolucão como cáncer, doenca pulmonar obstrutiva crônica e patologias reumáticas. Os tratamentos testados mais recentemente foram incluídos, como a terapia com luz intensa empregado em alteraçóes do ciclo sono-vigília.

Os diversos colaboradores exemplificam sua conduta pessoal, mostrando em detalhes estudos de casos. A tendência é de integração das várias modalidades terapêticas.

RUBENS REIMĀO

INFORMATION IN THE BRAIN: A MOLECULAR PERSPECTIVE. IRA B. BLACK. Um volume $(15,5 \times 23,5 \mathrm{~cm})$ encadernado, com 225 páginas. Cambridge: MIT Press, 1991. Endereç: The MIT Press, Cambridge, Massachussetts, USA.

Este não apenas um exemplo típico de toda uma corrente de pesquisadores procurancio explicar o funcionamento cerebral, seu comportamento correspondente e, em última análise, o mecanismo mental com base na perspectiva molecular. Em um esforco impressionante, Ira B. Black sintetiza conceitos abarcando cérebro, mente e comportamento em termos de bioquímica molecular e, ainda assim, continua a compreender as partes e mostrar o todo deste quadro complexo, de forma sintética.

A linguagem é direta e coloquial, tornando mais acessível o conteúdo. $O$ lautor focaliza conceitos novos, dinâmicos, dos circuitos neurais, das sinapses e do fluxo de informações. Nesta linha, busca compreender a bioquímica do processamento e do armazenamento de informações no sistema nervoso. Atém-se principłalmente às moléculas com função de sinais, transportadoras de informaçóes interneurais. Os estímulos internos ou do meio ambiente modificam tais moléculas e suas funções. Segundo Black, tais conceitos levam a mudanças na própria visão da imutabilidade da estrutura neural e das suas relacōes com o meio. Não mais vê o sistema nervoso como estrutura estática recebendo estímulos do meio e dando respostas estereotipadas. Pelo contrário, passa a compreendê-lo como a parte orgânica de todo um mundo biológico. Utilizanđo modelo de proliferação neural in vitro, demonstra como um dado neurônio exerce funções novas e variadas concomitantemente, abrangendo as metabólicas, as de comunicação e as simbólicas. Descreve a maneira de uma determinada célula neural usar numerosos transmissores para comunicar com outras células e consigo mesma, o conceito de co-localização. Uma população neural pode, assim, utilizar combinações distintas de sinais em tempos diferentes, dependendo do meio ambiente. Consequentemente, dentro de uma via neural anatômica, os circuitos químicos se formam, desfazem e voltam a se com- 
por dependendo de estímulos do meio. Tal sistema teria interface direta com o meio e interação reciproca constante, levando a um estado de fluxo contínuo de informação simbólica por meio de simbolos moleculares.

Conceitos dinamicos como os de polifunção, co-localização e interface com o meio povoam esta obra e estimulam a discussão entre os que se dedicam às neurociências.

\section{RUBENS REIMAO}

NEUROFISIOLOGIA PSICOLOGICA FUNDAMENTAL. J. JIMENEZ VARGAS \& A. POLAINO-LORENTE. Terceira Edição Ampliada. Barcelona: Editorial Científico-Médica, 1992 (Endereço: Via Layetana 53, Barcelona, Espanha).

O melhor elogio que se pode fazer a este livro é que satisfaz ao leitor, pois seus autores conseguem transmitir o que se propōem com o título dado a esta obra, ou seja, os fundamentos deste novo ramo das Neurociências que é a Fisiología Psicológica. Esses fundamentos são comunicados com rigor metodológico, apoiados em dados atualizados e reconhecidos, bioquimicos (especialmente dos neurotransmissores), farmacológicos, neurofisiológicos e análise do comportamento humano, entre outros. São eles apoiados, ainda, em referências bibliográficas recentes e selecionadis. Assim, os autores não caem em hipóteses, postulados ou extrapolaçōes subjetivas, frequentes em livros de Psicologia e em alguns de Neurologia. A finalidade desta obra é didática, dirigida a estudantes de Filosofia e Pedagogia, estando adequadamente ilustrada com figuras esquemáticas e claras, que ajudam a fixar conceitos fundamentais de Neurofisiologia, como também está enriquecida por tabelas do desenvolvimento ou amadurecimento, das diferentes funções do sistema nervoso do homem ao longo dos primeiros anos de vida.

Está dividida em 15 capítulos. Os três primeiros apresentam respectivamente, conceitos básicos e atualizados de morfologia, especialmente microscópica, do sistema nervoso, eletrofisiologia e neurotransmissores. Os três capítulos seguintes são dedicados à sensibilidade, tocando com protundidade no espinhoso tema da dor. Outros três capitulos são dedicados ao estudo das tunções sensoriais. No décimo capitulo é estudada a excitabilidade cerebral, passando conceitos acerca do sono, coma e morte cerebral. No décimo-primeiro capitulo estuda-se a motricidade. O décimo-segunao e décimo-quarto tratam com precisão das funçôes neuropsiquicas, conseguindo os autores deslindar os conhecimentos bem estabelecidos e aceitos, daqueles de dificil demonstração fisiológica, como por exemplo os fundamentos do pensamento, autoconsciência e inconsciente. Deixam ciaro as limitações da fisiologia para demongtrar essas características próprias da vida humana. O décimo-terceiro é dedicado ao sistema nervoso vegetativo, estudando-se a conduta instintiva. Definem os autores as caracteristicas dessa conduta no homem, assinalando as diferenças em relação a conduta animal. Também, delimitam as fronteiras entre as diversas funções orgânicas e os mecanismos estudados pela Cibernética. O último capitulo é dedicado às interrelações entre a Fisiologia e a Medicina Psícossomática. Termina a obra bom índice alfabético e um glossário, esclarecendo o significado de alguns termos usados em Fisiologia e Psicologia.

Esta obra, por seu caráter global, sem reducionismos, oferece ao leitor numerosos dados úteis e atualizados, para estar em dia a respeito das principais funções neurofisiológicas da pessoa humana, aplicáveis a clínica e terapêutica neurológicas. Por conseguinte, sua leitura agradará e será útil para todos os interessados nos diversos campos das Neurociências, inclusive aos que trabalham nas áreas da Psiquiatria e Psicologia.

JOSE L. ALONSO

PROPOSICIONES PARA UNA TEORIA DE LA MEDICINA. FERNANDO LOLAS STEPKE. Um volume $(11,5 \times 18 \mathrm{~cm})$ em brochura, com 213 páginas. Santiago: Editorial Universitaria, 1992. (Endereço: Maria Luisa Santander 0447, Santiago, Chile).

O grande cultor chileno das neurociências, Fernando Lolas, com este livro reabre o universo da crítica do conteúdo da medicina e do conteúdo crítico da medicina, oferecendo-o a avaliação. De sua parte, prende ele o leitor desde a primeira página, com a precisão dos conceitos que desnuda ao discuti-los, com a clareza de que reveste cada pensamento, assiun como pelo desencadeamento lógico dos assuntos, um gerando o outro. Para tanto muito o auxiliou sua formação humanística, da mesma forma que sua atividade como pesquisador, professor universitário e editor. De tudo resulta um texto cristalino e límpido, ta! como se, 
novo Novalis, nos despertasse para a indagação mediante o refletir sobre indagações que são fruto da própria medicina ou, ao inverso, servem de base para muitos de seus principiosi práticos. Assim, como ele próprio situa o compêndio, não é analisada uma teoria «da» medicina, mas «para» a medicina. Para tanto avaliar, muitas vezes utiliza o inverso, tal como em um novo jogo das contas de vidro. Como neste, a essência é avaliada peló fenômeno e o fenômeno, ele em si mesmo motivo de busca, é o aspecto abordável da essência. Como tal, permite visão fiel ou não, dependendo do modo pelo qual nós mesmos nos embrenhamos na procura de uma verdade, partindo da premissa de que esta existe e e importante, pelo menos para nós. Dentro desse aspecto conceitual desfilam, uma a uma, as idéias do Autor. Ele as reune em duas partes: da primeira consta a linha de argumentação; da segunda, particularizações motivadas por eventos.

Na primeira parte, «Para uma teoria de medicina como disciplina e como profissão", sucessivamente são avaliados: objetos e observadores; validade, verossimilhança, legitimidade; totalidade como perspectiva de descobrimento; profissionalização da ciência e da técnica; reducões da medicina como disciplina e como profissẽo; invariantes intrínsecas e extrínsecasł da medicina; busca de um estatuto teórico; medicina, ciência de açôes; ações do médico; objetivação cientifica do sofrimento; hegemonia da iatromedicina; limites da medicina; racionalidade da medicina; sistema de medicina iatrotécnica (biomedicina); iatrotécnicos em ação; dimensão social da medicina; visando a um bom modelo para a medicina. Na segunda parte encontram-se arrolados os títulos: integração das ciências biológicas e sociais; "situação básica", em medicina; bio-medicina o qualidade de vida; função testimonial do médico; postura publicitária e postura de comunicação; tecnologia biomédica, qualidade de vida e implicaçóes éticas; metáforas da razão médica; patologia teórica e antropologia médica; perspectivas biopsicossociais da enfermidade crônica; da ciência, idioma e psiquiatria; psiquiatria como saber-fazer; sanar e curar.

Da listagem dos assuntos abordados tem-se idéia do conteúdo do compêndio. Atualizado, cercado de referências bibliográficas, o Autor oferece visão panorâmica do conceito de medicina no contexto da informação no presente e versátil estágío da humanidade que vivemos. Como o próprio Autor recomenda na Apresentação, o livro Ł dirigido a profissionais e leigos. No entanto, ge cada um de nós, médicos, ler o livro sob o prisma do leigo, nele encontrará reflexo de sua própria essência como médico. Assim, a leitura deste livro enriquece a perspectiva médica e, ao mesmo tempo, oferece amplo material para meditação e análise por parte dos cultores das ciências do sistema nervoso. 